\title{
MEDIAÇÃO SANITÁRIA EM MEIO A PANDEMIA DO COVID - 19: INTERLOCUÇÕES DIALÓGICAS COM AS POLÍTICAS PÚBLICAS
}

\author{
Janaína Machado Sturza ${ }^{1}$ \\ Rosane Carvalho Porto ${ }^{2}$ \\ Jaqueline Beatriz Griebler ${ }^{3}$
}

\begin{abstract}
Resumo
Este artigo tem como objetivo analisar a possibilidade de aplicação da mediação sanitária, a partir de uma interlocução com as políticas públicas - especialmente no campo da saúde, levando-se em consideração o contexto atual da pandemia. Propõe como problema de pesquisa: a mediação sanitária pode ser utilizada como forma de solucionar casos envolvendo saúde, em meio a pandemia COVID-19? Como metodologia, utilizou-se o método dedutivo, a partir de um estudo bibliográfico. Concluiu-se que a mediação sanitária representa um importante instrumento de auxílio as políticas públicas, podendo ser utilizada na solução de questões sanitárias em meio a pandemia.
\end{abstract}

Palavras-chave: Mediação sanitária; pandemia; políticas públicas; saúde.

\section{HEALTH MEDIATION IN THE MIDDLE OF COVID'S PANDEMIC - 19: DIALOGICAL INTERLOCUTIONS WITH PUBLIC POLICIES}


current context of the pandemic. Proposes as a research problem: can health mediation be used as a way to solve cases involving health, in the midst of the COVID-19 pandemic? As a methodology, the deductive method was used, based on a bibliographic study. It was concluded that health mediation represents an important instrument to aid public policies, and can be used to solve health issues in the midst of a pandemic.

Keywords: Health mediation; pandemic; public policy; Cheers.

\section{INTRODUÇÃO}

É de conhecimento geral que o mundo vive uma grande crise sanitária, a qual vêm trazendo inúmeras consequências em todos os setores, sejam eles econômicos, sociais, sanitários e judiciais. A judicialização sanitária por sua vez, também tem enfrentado crescente demanda, onde cada vez mais casos são levados ao Poder Judiciário, buscando uma solução célere e eficaz, afinal, trata-se de questões envolvendo vidas.

Nesse sentido, tem-se visto cada vez mais, a adoção de outras alternativas e "planos B”, buscando soluções rápidas e certeiras para os casos envolvendo a pandemia e principalmente, a seara sanitária. As formas alternativas de solução de conflitos e as políticas públicas, acabam adquirindo seu espaço e sua credibilidade nesse momento, pois se mostram eficazes para garantir essa celeridade almejada. Assim, de modo principal na área sanitária, têm-se como problema central da presente pesquisa verificar se: a mediação sanitária pode ser utilizada como forma de reduzir e solucionar casos envolvendo saúde, principalmente em meio a pandemia COVID-19?

Outrossim, como objetivo central, procura-se estudar de modo genérico a pandemia, analisando o papel das políticas públicas para a população em geral, fazendo uma análise mais detalhada, na adoção da mediação sanitária, como forma de garantir o direito básico de acesso à justiça, aos cidadãos em meio a pandemia COVID-19, bem como verificando uma possível tendência mundial da mediação sanitária.

Como hipóteses, entende-se que a mediação sanitária pode sim ser aplicada, aliada à algumas políticas públicas de iniciativa do Poder Público, porém encontra alguns limites na vontade dos indivíduos em participar dela, bem como na aceitação que a população pode vir a ter ou não.

Por fim, como metodologia de pesquisa, utiliza-se o método dedutivo como método de abordagem e como métodos de procedimento, o histórico, com base em pesquisa bibliográfica 
e documental, fundamentada em livros, artigos científicos, revistas e períodos qualificados dentro da temática proposta. Ainda, o artigo é divido em três capítulos, no qual o primeiro aborda de forma geral a Pandemia da COVID-19 e o Estado de Calamidade Pública, o segundo aborda sobre as políticas públicas sanitárias e o direito a saúde e, por fim, no terceiro capítulo, é feito uma abordagem sobre a mediação sanitária e acesso à justiça em tempos de covid-19.

\section{A COVID-19 E O ESTADO DE CALAMIDADE PÚBLICA}

A palavra pandemia, possui origem grega e foi utilizada pela primeira vez por um pensador muito influente, Platão, em sua obra "Das Leis", tendo por significado genérico um fato ou acontecimento que alcance toda a população. No que tange a COVID-19, esta foi reconhecido como pandemia, pela OMS - Organização Mundial da Saúde, em março de 2020, tendo em vista a magnitude de proliferação mundial da doença (WERMUTH; MORAIS, 2020).

Em 30 de janeiro de 2020, a Organização Mundial de Saúde (OMS), por meio de seu diretor-geral, realizou uma declaração sobre o início de uma possível pandemia, momento este em que se ressaltou a necessidade de serem tomadas atitudes emergenciais, objetivando uma prevenção do vírus, que até então havia atingido com maior força, a China. Nas palavras do direitor-geral da OMS (WHO, 2020, s/p),

For all of these reasons, I am declaring a public health emergency of international concern over the global outbreak of novel coronavirus.

The main reason for this declaration is not because of what is happening in China, but because of what is happening in other countries.

Our greatest concern is the potential for the virus to spread to countries with weaker health systems, and which are ill-prepared to deal with it. ${ }^{4}$

Naquele momento, já se falava na proporção que a pandemia da COVID-19, poderia tomar pelo mundo e principalmente, nas consequências que causaria, especialmente nos locais em que o sistema de saúde não possui muitos recursos, maiormente de materiais e recursos

\footnotetext{
4 TRADUÇÃO: Por todas essas razões, declaro uma emergência de saúde pública de interesse internacional sobre o surto global de novos coronavírus. O principal motivo desta declaração não é o que está acontecendo na China, mas o que está acontecendo em outros países. Nossa maior preocupação é o potencial do vírus se espalhar para países com sistemas de saúde mais fracos e mal preparados para lidar com ele.
} 
financeiros, ou seja, indubitavelmente, os mais afetados, serão os países no qual o sistema de saúde é "fraco".

Outrossim, o Estado de Calamidade Pública no Brasil, foi decretado em 20 de março de 2020, a partir do Projeto de Decreto Legislativo (PDL) n ${ }^{\circ}$ 88/2020, o qual foi devidamente aprovado pelo Senado, em sessão ocorrida no mesmo dia. Este ato normativo foi realizado pelo Congresso Nacional, o qual foi promulgado por Antonio Anastasia, presidente em exercício do Senado. ${ }^{5}$

A partir de então, com o reconhecimento do Estado de Calamidade Pública no País, as atividades desenvolvidas, os recursos financeiros investidos, as notícias trazidas pelas mídias e principalmente as situações do dia a dia de toda a população, passaram a ser baseadas no assunto, pandemia da COVID-19, e a vida das pessoas, passou a ter um andamento e uma rotina diferenciadas. $\mathrm{O}$ ato normativo que decretou o Estado de Calamidade Pública no Brasil, tinha por objetivo permitir que o Executivo realizasse gastos diferenciados ao estipulado nas metas fiscais, porém acabou por mudar significativamente a vida de toda a população, principalmente no que diz respeito ao direito básico de saúde, o qual passou ser cada vez mais almejado e questionado.

Assim, Maiquel Ângelo Dezordi Wermuth e José Luis Bolzan de Morais (2020, p. 8), entendem que a crise e pandemia causadas pelo COVID-19, conhecido também por Coronavírus, acaba por causar na sociedade um estado de medo e insegurança e,

Este estado de medo e insegurança perene é potenciado, no caso do coronavírus, pelo fato de que o perigo - o inimigo - está dentro de nós mesmos. Trata-se, portanto, de um contexto de guerra contra um inimigo que - invisível - se esconde dentro de outros homens e que poderá deixar - assim como as guerras já vivenciadas pela humanidade - rastros nocivos que afetarão nosso futuro.

Outrossim, além de causar toda essa instabilidade e insegurança emocional, a pandemia enfrentada pelo mundo inteiro, vêm trazendo uma incerteza muito grande no que tange ao acesso à saúde e no Brasil de forma significativa, ao Sistema Único de Saúde - SUS, que atualmente é uma das maiores formas de garantia de um efetivo direito de acesso à saúde, mas que, assim como já vinha sofrendo alguns colapsos, questiona-se qual o seu possível futuro e principalmente, quais as políticas públicas que poderão/irão ser adotas a partir de

\footnotetext{
${ }^{5}$ Disponível para visualização deste no no no link: <https://legis.senado.leg.br/diarios/ver/103284?sequencia=377>.
} 
então, como forma de preservar a aplicabilidade deste direito à todos os cidadãos brasileiros. Nesse mesmo sentido, é possível destacar que a pandemia da Covid-19, "vem produzindo repercussões não apenas de ordem biomédica e epidemiológica em escala global, mas também repercussões e impactos sociais, econômicos, políticos, culturais e históricos sem precedentes na história recente das epidemias.” (FIOCRUZ, 2020).

Mateus de Oliveira Fornasier e Fernanda Viero da Silva (2020, s/p), mencionam que

Estudar como, normativamente, se pode facilitar a produção de bens e serviços essenciais, mesmo em tempos de crise, é fundamental não apenas para a sua superação, mas também, para que o processo de inovação tecnológica ocorra em tempo hábil.

Ademais e no que tange ao objeto de estudo desta pesquisa, vê-se necessário um estudo mais aprofundado, sobre políticas públicas e formas de atuação, que sustentem e garantam um acesso ao direito básico de saúde, frente à toda pandemia e com o surgimento de uma possível crise, seja ela de recursos financeiros, materiais e/ou também de pessoal.

\section{DAS POLÍTICAS PÚBLICAS SANITÁRIAS E DO DIREITO A SAÚDE}

As políticas públicas sanitárias consistem de fato em uma série de decisões que fazem fronte aos problemas individuais dos cidadãos nas questões de saúde. As decisões são presas aos organismos do governo, como exemplo o Ministério da Saúde e os vários departamentos e setores aos quais cabe a responsabilidade de promover as políticas públicas. Por conseguinte, para entender plenamente as políticas públicas sanitárias de um governo, é necessário considerar todas as decisões de todos os atores do governo envolvidos no financiamento e na gestão das decisões relativas à saúde (VICENZI; CAPANO, 2003, p. 9), levando-se em consideração que esta

[...] representa consequiência constitucional indissociável do direito a vida. O Poder Público, qualquer que seja a esfera institucional de sua atuação no plano da organização federativa brasileira, não pode mostrar-se indiferente ao problema da saúde da população sob pena de incidir, ainda que por censurável omissão, em grave comportamento inconstitucional (AgRg, 2001, p. 641).

Nesta perspectiva, a formulação das políticas públicas precisa ser uma ação muito bem articulada e transparente, demonstrando à sociedade, na pessoa do cidadão, o fim a que se 
destinam, lembrando que estas, por sua vez, devem ser sempre voltadas às necessidades da coletividade, visando o bem comum de toda a sociedade. Cada política pública compreende uma espécie de teoria de transformações sociais, teoria esta que significa regras e ações públicas, a partir das quais se constata os efeitos e impactos causados ao tecido social (FEBBRAJO; SPINA; RAITERI, 2006).

Frente a tais abordagens, é crível que se reconheça a todos os Poderes instituídos, em especial ao Judiciário, a competência e o dever institucional de se comprometerem com a efetivação das políticas públicas, protegendo quem efetivamente detém em última instância a soberania do poder - o povo, não por desvio ou excesso ideológico de crença política, mas pautado pela obrigação de garantir a ordem republicana e democrática de desenvolvimento do Brasil, sob pena de agravar ainda mais suas crises de identidade, eficácia e legitimidade social (LEAL, 2006).

Não obstante, pode-se dizer que as questões judiciais sobre a saúde trazem consigo a polêmica temática das políticas públicas, sendo que por esta razão há que se discutir também sobre a judicialização da política ${ }^{6}$, a qual pode ser entendida como a utilização de procedimentos judiciais para a resolução de conflitos de ordem política, tais como controvérsias acerca de normas, resoluções e políticas públicas adotadas e implementadas pelos Poderes Executivo e Legislativo, uma vez que, nos dias atuais, há quem defenda a busca e concretização das políticas públicas através do judiciário, ou mais precisamente, através da judicialização da política (OLIVEIRA, 2005), sendo tal fato uma forma de proteção à saúde, na ausência de um mecanismo específico.

Esta judicialização, centrada também na interpretação da Constituição, mais precisamente no controle da Constituição exercido pelo STF em sua forma concentrada e pelos demais tribunais em sua forma difusa, seria a maneira do judiciário constituir-se em uma instância de implementação e concretização de direitos sociais e coletivos, ocorrendo tal fato devido à perda da capacidade de promoção do bem estar social que o Estado teve a partir do momento em que adotou uma ideologia neoliberal. Todavia, não se pode dizer que houve uma mudança positiva em relação à eficácia das políticas públicas devido a judicialização da política, haja visto que quando ocorre o controle difuso, ou melhor, o controle de um caso específico pelos tribunais estaduais, tão somente a pessoa que entrou com a ação será a

\footnotetext{
6 Sobre o tema da judicialização das políticas públicas, ver também: VIANNA, Luiz Werneck et al. $A$ judicialização da política e das relações sociais no Brasil. Rio de Janeiro, Revan, 1999.
} 
favorecida, tendo as demais, lesionadas da mesma forma, que reclamar por seus direitos (ARANTES, 2005).

Como é possível constatar-se, a judicialização da política não se constitui como a melhor forma de criação e implementação das políticas públicas sanitárias, tão pouco de concretização dos direitos fundamentais, aqui em especial o direito à saúde. Entretanto, é uma via pela qual as pessoas podem buscar por seus direitos, muitas vezes negligenciados por quem deveria assegurá-los. Logo, o direito à saúde no Brasil, como aponta a Constituição Federal de 1988, é um direito de todos e um dever do Estado, calcado no art. 196 da Constituição e garantido mediante políticas sociais e econômicas que visam à redução do risco de doenças e de outros agravos e ao acesso universal e igualitário às ações e serviços para sua promoção, proteção e recuperação. Através deste dispositivo legal o termo saúde constitui-se como um direito reconhecido igualmente a todo o povo, além de ser um meio de preservação e, acima de tudo, de qualidade de vida, sendo esta o bem máximo da humanidade.

A saúde, na sociedade contemporânea, apresenta-se como uma prerrogativa essencial à vida do homem, ao mesmo tempo em que, nas muitas situações da vida diária, acaba sendo ameaçada. A saúde é primordial ao ser humano que, na sua individualidade, necessita de uma garantia a este direito fundamental à sua sobrevivência, uma vez que, em sociedades ditas democráticas, as dificuldades residem justamente em permitir a manutenção da saúde em um mundo onde os riscos também são globalizados.

Hoje, a saúde é indiscutivelmente um fundamental direito humano, além de ser também um importante investimento social. Na medida em que os governos têm o objetivo de melhorar as condições de saúde de todos os cidadãos, é necessário que invistam recursos em políticas públicas de saúde, capazes de garantirem programas efetivos para a sua promoção. Nesta perspectiva, surge um espaço onde o direito moderno pode ser estudado, aplicado e refletido, não apenas como tradicionalmente vem ocorrendo, a partir da ótica dogmática e formalista, mas sim através de uma proposta.

Ademais, por mais que é um direito fundamental garantido à todos os cidadãos pela Carta Magna, sabe-se que nem sempre este é efetivamente colocado à disposição e tendo seu acesso livre, sendo necessária, como já mencionado, algumas intervenções jurídicas, buscando sua garantia. Assim, pode-se afirmar como opção de viabilizar esse acesso ao direito violado, a Mediação Sanitária, a qual inclusive em tempos de pandemia, pode trazer inúmeros benefícios e resultados positivos, quando aplicada com seriedade. Sendo assim, 
após toda análise referente ao direito básico de saúde e também questões pontuais sobre a pandemia e Estado de Calamidade Pública enfrentado pelo mundo e de forma especial neste estudo, pelo Brasil, importante trazer à baila, algumas questões relevantes sobre o acesso à justiça, por meio da Mediação Sanitária.

\section{MEDIAÇÃO SANITÁRIA E ACESSO À JUSTIÇA EM TEMPOS DE COVID-19}

Os atuais tempos, em que a crise de valores das sociedades está acentuada por conta de diversos fatores, tais como: desigualdade social, machismo e racismo estrutural, desemprego e a crise sanitária, tem sido recorrente e desafiador ao Estado e as instituições assegurarem e garantirem o acesso à justiça dos cidadãos. Nesse contexto surgem e aumentam as demandas sociais e também de saúde pública que acabam parando e sendo judicializadas no Poder Judiciário. É importante destacar que a judicialização de tais demandas nem sempre são sinônimos de acesso ou garantia aos direitos pela via da justiça.

Embora sejam inúmeras as demandas destacar-se-á as oriundas ou ainda que advirão por causa da crise sanitária desencadeada, principalmente pela COVID 19. Existem outros meios de autocomposição e potencializados de diálogo social, que podem dar lugar a fraternidade. Dos vários meios autocompositivos de solução de conflitos, destacar-se-á a mediação sanitária e ainda, ousando afirmar a partir do pesquisador Ivo Aertsen ${ }^{7}$ (OAB/RS, 2018), ela é fundamental para o desenvolvimento social e pode ser emprestada para redimensionar e conhecer como uma prática restaurativa. Antes de abordar sobre a possibilidade de mediação sanitária para o enfrentamento a crise pandêmica dada pelo COVID19, dois pontos merecem destaque. Primeiro, é fundamental analisar os institutos sanitários, por exemplo, o sistema de saúde do Brasil (SUS) a partir da perspectiva de um direito global sanitário, emanado de Organizações internacionais e com a cooperação

\footnotetext{
${ }^{7}$ Aertsen defende que: “A mediação surge como uma alternativa para alcançar a solução de conflitos, de maneira extrajudicial e por meio de um convite à reflexão e negociação, além de ser adotado na perspectiva penal e na perspectiva civil. Para o coordenador da linha de pesquisa em Justiça Restaurativa e Vitimologia do Instituto de Criminologia de Leuven, da Universidade de Leuven na Bélgica, e uma das referências mundiais no tema, Ivo Aertsen, a mediação é fundamental para o desenvolvimento da sociedade. Além disso, ele acredita que a população pode ter um papel importante na construção de uma ordem social mais pacificada." Entrevista disponível em: http://jornaldaordem.com.br/noticia-ler/entrevista-uma-das-referencias-mundiais-no-tema-justicarestaurativa-ivo-aertsen-na-casa-mediacao-oa/43335.
} 
internacional de todos os órgãos, conforme bem destacou Joaquín Cayón, em sua Palestra de 09 de junho de $2020^{8}$.

Em segundo momento, é necessário fazer uma reflexão de qual o lugar da mediação sanitária em meio ao COVID19? No âmbito internacional, junto a esse questionamento está qual o papel dos Estados nesta pandemia, pois o fortalecimento do Estado-nação não pode ser ressignificado por delírios de um Estado de exceção. A crise sanitária precisa deixar de ser uma política de oportunidades e sim dar espaço ao princípio da fraternidade pela via do diálogo social. Assim, mais do que nunca a ponderação sanitária com o sistema da política é um caminho apontado por Joaquim Cayon em sua palestra ${ }^{9}$, para o enfrentamento de problemas complexos, que requeiram soluções complexas. Significa dizer, os problemas complexos não podem buscar respostas simplistas. As respostas precisam se dar de maneira transdisciplinar e isso exige mudança de comportamentos, de mentalidades e de ressignificação de conceitos jurídicos postos. Por tal motivo, entende-se que a mediação sanitária, realizada de forma global e internacional, poderia trazer inúmeros benefícios para tratar e resolver questões relacionadas à saúde pública e assim, tomar-se medidas cada vez maiores e mais fortes, com um poder internacional, tendo em vista, que no Brasil, conforme se verá mais adiante, muitas já são as práticas de mediação aplicadas em assuntos sanitários.

Outrossim, no que tange ao acesso à justiça, pode-se afirmar que este é um direito fundamental de todo o cidadão que busca dentro do seu Estado e da sua sociedade respaldo jurídico para assegurar a proteção e as garantias dos seus direitos. Abordar sobre este direito não é tarefa simples, no atual cenário político, econômico e jurídico brasileiro. Porém, é relevante tratar e relembrar o quanto ter reconhecido como um direito fundamental a pessoa representou uma conquista, também por conta do recepcionamento da mediação sanitária nos embates sociais, políticos e econômicos envolvendo a saúde pública; e atualmente relacionada a ela, o problema do COVID-19.

Inexoravelmente o estado de exceção ou de calamidade pública posto pela pandemia de ordem global atinge o direito fundamental humano e básico das pessoas que é o acesso à justiça, bem como a outra via o acesso a jurisdição. Ambas as terminologias são distintas uma

\footnotetext{
${ }^{8}$ Em 09 de junho de 2020, Joaquín Cayón realizou uma palestra no Evento: II ENCONTRO DE GRUPOS DE PESQUISA: GPBioDH/UNIJUÍ e GPDH \& Transformações Sociais/UNIRITTER, sobre Marco Jurídico de las medidas anti-Covid em España.

${ }^{9}$ Em 09 de junho de 2020, Joaquín Cayón realizou uma palestra no Evento: II ENCONTRO DE GRUPOS DE PESQUISA: GPBioDH/UNIJUÍ e GPDH \& Transformações Sociais/UNIRITTER, sobre Marco Jurídico de las medidas anti-Covid em España.
} 
da outra, porém, relacionam-se, pois o acesso a jurisdição diz respeito ao cidadão acessar os serviços pelos profissionais do direito; em outras palavras, a tutela jurisdicional do Estado.

O sistema judicial de muitos países latino-americanos, como europeus, africanos e asiáticos passaram por reformas, se tornando protagonistas do contexto sócio jurídico. No entanto, mesmo com a criação de outras políticas de gestão, como no caso do Brasil que criou o Conselho Nacional de Justiça (CNJ), para modernizar o Judiciário e se tornar uma justiça de proximidade, dialogando com a comunidade e qualificando a sua prestação de serviço, ainda carece de modernidade, eficácia e eficiência nas suas políticas públicas de tratamento de conflitos.

Segundo Santos (2007), o protagonismo dos tribunais emerge desta mudança política havendo a necessidade de ruptura do neoliberalismo europeu para o liberalismo americano. Entre outras circunstâncias, mister um Judiciário eficaz, rápido e independente. Nesse contexto de necessárias mudanças, está a precarização dos direitos econômicos e sociais passando a ser um motivo de procura do Judiciário. "O que significa que a litigância tem a ver com culturas jurídicas e políticas, mas tem a ver, também, com um nível de efetividade da aplicação dos direitos e com a existência de estruturas administrativas que sustentam essa aplicação" (SANTOS, 2007, p. 17).

De outra banda, pode-se dizer que a crise do Judiciário é decorrente de uma crise maior, a crise do Estado contemporâneo, aliada à crise do Direito e do processo, pois não funciona mais o sistema processual tradicional, com a morosidade da prestação jurisdicional, com o seu formalismo exacerbado, oriundo do positivismo jurídico. Embora as diversas medidas adotadas pelo Judiciário no sentido de solucionar os problemas apresentados, elas ainda são insuficientes. Contudo, o Judiciário brasileiro está acompanhando o movimento de reformas adotadas por outros países, visando solucionar os obstáculos que inviabilizam o acesso à justiça (AMARAL, 2009).

Sabe-se que o conflito é bastante comum entre os seres humanos, tendo em vista a disputa pelos bens da vida, sendo poucos os bens e muitos os interesses. Há três diferentes formas de se obter a solução de um conflito de interesses: autotutela (ou autodefesa), autocomposição e heterocomposição (AMARAL, 2009).

Não se pode perder de vista, também, que o aparato judicial, para tratar os conflitos atuais, serve-se de instrumentos e códigos muitas vezes ultrapassados, ainda que formalmente em vigor, com acanhado alcance e eficácia reduzida. Tal eficácia e alcance muitas vezes 
atingem somente os conflitos interindividuais, não extrapolando o domínio privado das partes, encontrando dificuldades quando instado a tratar de direitos coletivos ou difusos (SPENGLER, 2010).

O conceito de acesso à justiça tem sofrido uma transformação importante, correspondente a uma mudança equivalente no estudo e ensino do processo civil. A teoria era de que, embora o acesso à justiça pudesse ser um "direito natural", os direitos naturais não necessitavam de uma ação do Estado para sua proteção. Esses direitos eram considerados anteriores ao Estado; sua preservação exigia apenas que o Estado não permitisse que eles fossem infringidos por outros. De fato, o direito ao acesso efetivo tem sido progressivamente reconhecido como sendo de importância capital entre os novos direitos individuais e sociais, uma vez que a titularidade de direitos é destituída de sentido, na ausência de mecanismos para sua efetiva reivindicação (CAPPELLETTI; GARTH, 2002).

Mauro Cappelletti e Bryant Garth (2002) estabeleceram uma subdivisão cronológica dos movimentos de acesso à justiça, ou seja, de tentativas de soluções para se garantir a efetividade do acesso à justiça, e cada movimento foi chamado pelos autores de "onda". A primeira "onda" teria sido a assistência judiciária; a segunda referia-se à representação jurídica para os interesses difusos, especialmente nas áreas de proteção ambiental e do consumidor e, finalmente, a terceira "onda" que seria o "enfoque de acesso à justiça", a qual compreendia os posicionamentos anteriores e tinha como objetivo enfrentar contundente e articuladamente, as barreiras ao acesso efetivo à justiça (CAPPELLETTI; GARTH, 2002).

Desveladas algumas das facetas da judicialização naquilo que desestabiliza a organização do sistema de saúde brasileiro, impõe-se a procura de um outro meio eficaz de justiça, um tanto menos intervencionista e mais consensualista, integrado à realidade do país, e que contemple de modo igualitário a oferta de bens e serviços de saúde à sociedade. Nesse sentido a ideia de desjudicialização não se trata de medida apenas com o objetivo de desonerar o Poder público e contribuir para a celeridade processual no Judiciário, mas principalmente de concretizar o direito à saúde e do acesso à justiça como estabelecido na Constituição Federal de 1988 e nas demais legislações extravagantes.

E para isso, dada a epidemia devido ao coronavírus COVID-19, a mediação sanitária pode ser uma via propulsora de diálogo de diversos atores, dentre eles sociedade civil, gestores públicos, médicos, para o implemento de políticas públicas sanitárias que tenham natureza preventiva e não possam implicar judicialização do direito à saúde. Com a 
publicação da Resolução número 125 de 2010 pelo Conselho Nacional de Justiça (CNJ) que versa sobre a política Judicial Nacional de tratamento adequado de conflitos do âmbito do Poder Judiciário, a mediação passa a ser reconhecida como sendo um modelo alternativo para resolução de conflitos, ganhando reconhecimento e notoriedade com o seu recepcionamento em 16 de março de 2015 com a promulgação da Lei 13.105, a qual entrou em vigor no dia 18 de março de 2016 e instituiu o novo Código de Processo Civil (CPC). Em 26 de junho de 2015, foi sancionada a lei 13.140, com o objetivo de dispor sobre a mediação entre particulares com meio de solução de controvérsias e sobre autocomposição de conflitos no âmbito da administração pública (SPENGLER; DA COSTA, 2019).

Nesse contexto, tem-se buscado implementar, mesmo que ainda de maneira embrionária a mediação para solução autocompositiva de demandas na área da saúde, para prevenir a judicialização e construir conjuntamente estratégias que viabilizem políticas públicas sanitárias aos cidadãos pela via do diálogo e comprometimento de todos os envolvidos, destacando gestores públicos, sociedade civil e demais poderes institucionalizados (DELDUQUE; CASTRO, 2015). A título de exemplificação tem-se a Câmara especializada em questões de saúde com a finalidade de mediar conflitos entre pacientes e usuários do SUS e os gestores da rede pública de saúde na cidade de Brasília. Na Câmara Permanente Distrital de Mediação em Saúde, da Defensoria Pública do Distrito Federal (CAMEDIS), criada em fevereiro de 2013 por meio de portaria conjunta entre a Secretaria de Saúde e a Defensoria Pública), a Defensoria, via de regra, deixa de ingressar judicialmente com as demandas de saúde dos pacientes, para também a buscar soluções extrajudiciais para os conflitos, por meio da prática da mediação, ou seja, de uma melhor proximidade nas reuniões com os envolvidos (PAIM; MARQUETO; LOPES, 2020).

Ainda, no que tange aos projetos brasileiros já implementados na área da mediação sanitária, cite-se o Estado do Rio de Janeiro, onde foi criada a Câmara de Resolução de Litígios de Saúde (CRLS), um projeto de cooperação que reúne as Procuradorias Gerais do Estado e do Município do Rio de Janeiro, além das Secretarias Estadual e Municipal de Saúde, as Defensorias Estadual e da União, além do Tribunal de Justiça do Estado. O objetivo da Câmara é buscar soluções administrativas para o atendimento de cidadãos que precisam de medicamentos, exames, internações, tratamentos e transferências do SUS, evitando o ajuizamento de ações. 
No Estado do Rio Grande do Sul (PGERS) em março de 2017, com a premissa de mudar esse cenário e racionalizar a atuação judicial e extrajudicial nos conflitos de saúde, foi criado pela Procuradoria-Geral do Estado o programa Resolve + Saúde, que visa mapear as principais demandas e os medicamentos mais solicitados e, a partir disso, propor soluções dirigidas para reduzir os gastos decorrentes do excessivo acesso ao judiciário para resolver questões ligadas à saúde pública, acrescenta a informação (PGE-RS, 2020). Um dos objetivos do projeto é, em parceria com a Secretaria da Saúde, otimizar a dispensação de medicamentos na via administrativa, reduzindo com isso a judicialização da saúde e os bloqueios judiciais, bem como preservar as diretrizes e princípios do SUS. Posteriormente, o projeto visa buscar a implementação de uma instância administrativa para a solução de demandas de saúde, reduzindo-se a judicialização propriamente dita (PGE-RS, 2020).

Essas experiências demonstram a possibilidade de trabalhar com a mediação sanitária no âmbito local. Poder-se-ia ir além das fronteiras brasileiras quando se está à frente e na luta global contra a pandemia COVID-19, suscitando a propositura da mediação sanitária planetária, tendo no centro como principal mediador a OMS (Organização Mundial de Saúde) para estabelecer diretrizes e regras que tivessem como ponto comum, a sobrevivência humana. Nesse momento é fundamental o exercício da solidariedade global e a diplomacia entre os países, pois a doença é comum, sendo urgente um pensar coletivamente em termos de políticas públicas voltadas a saúde, bem como ressignificar o sentido de fronteiras, soberania e bem comum.

Outrossim, Wermuth e Morais (2020), defendem que a crise sanitária causada pelo COVID-19, pode ser vista com outros olhos e sob outra perspectiva, uma vez que ao contrário de produzir um distanciamento social, poderá auxiliar na produção de novos vínculos e reestabelecer àqueles que encontram-se afetados e perdidos. Ainda assim, é possível afirmar que a restrição à liberdade imposta pela maioria dos governos mundiais, além de buscar a proteção à vida da população, também objetivam dar uma maior capacidade de resposta ao sistema de saúde, frente a todas as situações que terão de enfrentar e principalmente, pelos inúmeros casos graves de saúde que terão a necessidade de atender com maior atenção e qualidade plena (WERMUTH; MORAIS, 2020).

De outro modo, de acordo com os pensamentos e posicionamentos de Yuval Noah Harari, pode-se transcrever que "as crises globais contemporâneas - dentre as quais está a pandemia do Covid-19 - podem ser atribuídas à falta de confiança entre os seres humanos" 
(WERMUTH; MORAIS, 2020, p. 13). Nesse sentido, para que se busque resultados positivos ou pelo menos, uma melhora em relação à pandemias como a que se sofre atualmente no mundo, é necessário que haja efetivamente uma cultura de confiança, confiança esta que deve ser verdadeira, tanto em especialistas, autoridades públicas, cientistas e principalmente, entre países e populações do mundo.

Por fim, pode-se destacar que, a partir dessa necessidade de confiança global que se busca, principalmente em tempos de crise, Luigi Ferrajoli defende a ideia da necessidade de um "constitucionalismo planetário", ideia esta que "parte do pressuposto de que crises globais - a exemplo das questões ambientais e, recentemente, a pandemia do Covid-19 - exigem respostas globais que tenham a mesma dimensão e eficácia.” (WERMUTH; MORAIS, 2020, p. 14). É necessário que, as atitudes sejam tomadas em níveis globais, de forma concomitante e iguais, para que possa se falar em contenção e redução do caos existente. Assim, seria possível evitar medidas totalmente esparsas pelo cenário mundial, na qual algumas agem com maior rigidez, já outras, com uma flexibilização surpreendente.

\section{CONSIDERAÇÕES FINAIS}

Com base em todos os fatos mencionados, pode-se concluir que, a palavra pandemia, possui origem grega e significa um fato ou acontecimento que alcance toda a população. No que tange ao COVID-19, este foi reconhecido como pandemia, pela OMS - Organização Mundial da Saúde, em março de 2020, tendo em vista a magnitude de proliferação mundial da doença. Outrossim, o Estado de Calamidade Pública no Brasil, foi decretado em 20 de março de 2020, a partir do Projeto de Decreto Legislativo (PDL) n ${ }^{\circ}$ 88/2020, o qual foi devidamente aprovado pelo Senado, em sessão ocorrida no mesmo dia. A partir de então, o país passou a ter um rumo diferenciado e principalmente a saúde pública passou a ser um direito cada vez mais discutido e necessário.

Já, no que tange ao direito básico de saúde no Brasil, é possível afirmar que, como aponta a nossa Constituição Federal de 1988, é um direito de todos e um dever do Estado, calcado no art. 196 da Constituição e garantido mediante políticas sociais e econômicas que visam à redução do risco de doença e de outros agravos e ao acesso universal e igualitário às ações e serviços para sua promoção, proteção e recuperação. Através deste dispositivo legal o 
termo saúde se constituiu como um direito reconhecido igualmente a todo o povo, além de ser um meio de preservação e de qualidade de vida.

Porém, nem sempre este direito é concedido de forma eficaz à todos, necessitando a busca de um outro meio eficaz de justiça, que garanta a plenitude do mesmo. Acontece que, em tempos de pandemia, o Poder Judiciário também poderá ser comprometido, tendo em vista a quantidade de demandas que surgirem, fato este que traz a necessidade de buscar um outro meio, um tanto menos intervencionista e mais consensualista, integrado à realidade do país, e que contemple de modo igualitário a oferta de bens e serviços de saúde à sociedade.

Nesse sentido a ideia de desjudicialização não se trata de medida apenas com o objetivo de desonerar o Poder público e contribuir para a celeridade processual no Judiciário, mas principalmente de concretizar o direito à saúde e do acesso à justiça como estabelecido na Constituição Federal de 1988 e nas demais legislações extravagantes. E para isso, dada a epidemia devido ao coronavírus COVID-19, a mediação sanitária se apresenta como uma via propulsora de diálogo de diversos atores, dentre eles sociedade civil, gestores públicos, médicos, para o implemento de políticas públicas sanitárias que tenham natureza preventiva e não possam implicar judicialização do direito à saúde.

Muitos são os projetos que já tem trazido resultados positivos em âmbito brasileiro, da aplicação da mediação sanitária e que, em épocas de pandemia da COVID-19, poderiam vir como uma ferramenta eficaz no tratamento de questões conflitivas relacionadas ao direito à saúde. A título de exemplificação tem-se a Câmara Permanente Distrital de Mediação em Saúde, da Defensoria Pública do Distrito Federal (CAMEDIS), criada em fevereiro de 2013 por meio de portaria conjunta entre a Secretaria de Saúde e a Defensoria Pública, também, no Estado do Rio de Janeiro, a Câmara de Resolução de Litígios de Saúde (CRLS), um projeto de cooperação que reúne as Procuradorias Gerais do Estado e do Município do Rio de Janeiro, além das Secretarias Estadual e Municipal de Saúde, as Defensorias Estadual e da União, além do Tribunal de Justiça do Estado e no Estado do Rio Grande do Sul (PGERS) criado em março de 2017, o programa Resolve + Saúde.

Essas experiências demonstram a possibilidade de trabalhar com a mediação sanitária no âmbito local e principalmente mundial, por meio da Organização Mundial de Saúde (OMS), principalmente quando se está diante de uma pandemia, como a que o mundo vem sofrendo, trazendo como positiva, a resposta ao questionamento base dessa pesquisa. Dessa forma, e analisando todas os projetos e iniciativas mencionadas, é possível afirmar que a 
mediação sanitária pode ser um importante aliado à garantia de um efetivo acesso à justiça e principalmente, ao direito básico de saúde, em tempos de COVID-19, momento este que estes direitos podem ser fortemente violados, a partir de uma possível crise que está por vir e principalmente, pela quantidade de demandas que passam a surgir em ambos os ambientes, tanto saúde pública como Poder Judiciário.

\section{REFERÊNCIAS}

AgRg no RE no. 271.286-8/RS, rel. Min. Celso de Mello, J. Em 12.9.2000, Boletim de Direito Administrativo, ago. 2001, p. 641.

AMARAL, Márcia Terezinha Gomes. O Direito de acesso à justiça e a mediação. Rio de Janeiro: Lumen Juris, 2009, p.49.

ARANTES, Rogério. Judiciário: entre a justiça e a política. In AVELAR, Lúcia; CINTRA, Antônio Octávio (organizadores). Sistema político brasileiro: uma introdução. Rio de Janeiro/São Paulo, Fundação Konrad Adenauer/UNESP, Cap. 3, p. 79-108, 2005.

CAPPELLETTI, Mauro; GARTH, Bryant. Acesso à justiça. Tradução de Ellem Gracie Northfleet. Porto Alegre: Fabris, 2002.

DELDUQUE, Maria Célia; CASTRO, Eduardo Vazquez de. A Mediação Sanitária como alternativa viável à judicialização das políticas de saúde no Brasil. Disponível em: https://www.scielo.br/scielo.php?pid=S0103-

11042015000200506\&script=sci_arttext\&tlng=pt. Acesso em: 10 Set. 2020.

FEBBRAJO, Alberto; SPINA, Antonio La; RAITERI, Monica. Cultura giuridica e politiche pubbliche in Italia. Milano, Giuffrè, 2006, passim.

FIOCRUZ, Fundação Oswaldo Cruz. Impactos sociais, econômicos, culturais e políticos da pandemia. Disponível em: https://portal.fiocruz.br/impactos-sociais-economicos-culturais-epoliticos-da-pandemia. Acesso em: 19 Set. 2020.

FORNASIER, Mateus de Oliveira; SILVA, Fernanda Viero da. PESQUISA JURÍDICA COMO CATALISADORA DE PROCESSOS DE INOVAÇÃO E PRODUÇÃO NECESSÁRIOS EM ÉPOCAS DE CRISE SANITÁRIA E HUMANITÁRIA. Disponível em: < https://sites.google.com/a/unijui.edu.br/ciencia-explica-covid-19/ciencia-sobre-covid19/n12-a-pesquisa-jur\%C3\%ADdica-inova\%C3\%A7\%C3\%A3o-eprodu\%C3\%A7\%C3\%A3o-em-\%C3\%A9pocas-de-crise> Acesso em: 16 abr. 2020.

LEAL, Rogério Gesta. O controle jurisdicional de políticas públicas no Brasil: possibilidades materiais. Revista de derecho, v. 9, p. 53-66, 2006.

$\mathrm{OAB} / \mathrm{RS}$, Jornal da Ordem. Entrevista com uma das referências mundiais no tema justiça restaurativa, Ivo Aertsen na Casa de Mediação da OAB/RS. Disponível em: 
http://jornaldaordem.com.br/noticia-ler/entrevista-uma-das-referencias-mundiais-no-temajustica-restaurativa-ivo-aertsen-na-casa-mediacao-oa/43335. Acesso em: 26 Set. 2020.

OLIVEIRA, Vanessa. Judiciário e privatizações no Brasil: existe uma judicialização da política? Revista de Ciências Sociais, Rio de Janeiro, v. 48, n. 3, p. 559-587, 2005.

PAIM, Patrícia; MARQUETO, Alessandra; LOPES, Ivaneide de Oliveira. Câmara Permanente Distrital de Mediação em Saúde: experiência do Distrito Federal. 1. ed. Brasília: Conselho Nacional de Secretários de Saúde - CONASS, 2015 Disponível em <www.conass.org.br>. Acesso em: 10 Set. 2020.

PROCURADORIA-GERAL DO ESTADO DO RIO GRANDE DO SUL. PGE-RS entrega Relatório de Atividades 2016 ao Governador José Ivo Sartori. Notícias, 23/05/2017a. Disponível em: <http://www.pge.rs.gov.br/pge-rs-entrega-relatorio-de-atividades-2016-aogovernador-jose-ivo-sartori>. Acesso em: 10 Set. 2020.

PROCURADORIA-GERAL DO ESTADO DO RIO GRANDE DO SUL. PGE-RS apresenta alternativas para reduzir judicialização da saúde. Notícias, 24/07/2017b. Disponível em: <http://www.pge.rs.gov.br/pge-rs-apresenta-alternativas-para-reduzirjudicializacao-da-saude>. Acesso em 10 Set. 2020.

SANTOS, Boaventura Sousa. Para uma revolução democrática da justiça. São Paulo: Cortez, 2007. - (Coleção questões da nossa época; v. 134), p.17.

SPENGLER, Fabiana Marion. Da jurisdição à mediação: por uma outra cultura no tratamento de conflitos. Ijuí: Ed. Unijuí, 2010.

SPENGLER, Fabiana Marion; DA COSTA, Márcio Dutra. Mediación procesal de conflictos colectivos en la justicia del trabajo brasileña . REVISTA CHILENA DE DERECHO DEL TRABAJO Y DE LA SEGURIDAD SOCIAL VOL. 10 NÚM. 19 (2019) PÁGS. 41-62.

VINCENZI, Alessandra. CAPANO, Giliberto. Come studiare le politiche pubbliche. Bologna, Il Mulino, 2003, p.9.

WERMUTH, Maiquel Ângelo Dezordi; MORAIS, José Luis Bolzan de. Da exceção Agambeniana à constituição planetária de Ferrajoli: desafios impostos pela pandemia do novo coronavírus às categorias jurídico-políticas tradicionais. In: Revista Eletrônica do Curso de Direito da UFSM. v. 15, n. 1 / 2020 e43057

WHO, World Health Organization. WHO Director-General's statement on IHR Emergency Committee on Novel Coronavirus (2019-nCoV). Disponível em: < https://www.who.int/dg/speeches/detail/who-director-general-s-statement-on-ihr-emergencycommittee-on-novel-coronavirus-(2019-ncov)> Acesso em: 16 abr. 2020. 
